\title{
Manganese oxide electrochemical capacitor with potassium poly(acrylate) hydrogel electrolyte
}

\author{
Kuang-Tsin Lee, Nae-Lih $\mathrm{Wu}^{*}$ \\ Department of Chemical Engineering, National Taiwan University, Taipei 106, Taiwan
}

Received 21 September 2007; received in revised form 13 December 2007; accepted 17 December 2007

Available online 26 December 2007

\begin{abstract}
An aqueous gel electrolyte has for the first time been successfully applied to the $\mathrm{MnO}_{2} \cdot n \mathrm{H}_{2} \mathrm{O}$-based pseudocapacitive electrochemical capacitors (ECs). The gel electrolyte is made of potassium poly(acrylate) (PAAK) polymer and aqueous solution of KCl. With the selected composition, PAAK: $\mathrm{KCl}: \mathrm{H}_{2} \mathrm{O}=9.0 \%: 6.7 \%: 84.3 \%$ by weight, the gel shows no fluidity, possessing an ionic conductivity in the order of $10^{-1} \mathrm{~S} \mathrm{~cm}{ }^{-1}$. The gel electrolyte has been found to give substantially higher specific capacitances than those in the liquid electrolyte with the same salt (KCl) composition (1 M) and high power capability (>10 kW/kg).
\end{abstract}

(C) 2008 Elsevier B.V. All rights reserved.

Keywords: Electrochemical capacitor; $\mathrm{MnO}_{2}$; Gel electrolyte; Potassium poly(acrylate)

\section{Introduction}

Electrochemical capacitors (ECs) are promising energy storage devices for the high-power electric market [1-3]. For practical applications, an EC requires not only good electrochemical performance but also high safety standard. Hydrated amorphous/nanocrystalline manganese oxide, $\mathrm{MnO}_{2} \cdot n \mathrm{H}_{2} \mathrm{O}$ [4,5], has drawn much attention as a promising EC electrode material. It exhibits high capacitances, in the range of 100-200 F/g for the powder-based thick-film electrodes and up to $700 \mathrm{~F} / \mathrm{g}$ for thin-film ones, and high-rate capability in several neutral aqueous electrolytes of alkali salts [4-9]. Compared with $\mathrm{RuO}_{2}$-based ECs [10,11], which use strong acidic electrolytes, the $\mathrm{MnO}_{2}$ ECs have the advantages of low cost and environment-benign nature.

To date, ECs have mainly employed liquid solution electrolytes. Replacing the liquid electrolytes with solid electrolytes will enhance the safety and reliability of ECs, as it will prevent problems associated with electrolyte leakage and corrosion. However, polymeric solid electrolytes suffer from disadvantages of low ionic conductivity and hence high resistance, which are particularly detrimental to high-power applications. Poly-

\footnotetext{
* Corresponding author. Tel.: +886223627158.

E-mail address: nlw001@ntu.edu.tw (N.-L. Wu).
}

meric gel electrolytes, on one hand, can give sufficient rigidity for enhancing device safety, and on the other, could provide much higher ionic conductivity than the solid ones. Although there have been reports on applying strong alkaline and acidic gel electrolytes to the electric double-layer capacitors (EDLCs) [12-15] and $\mathrm{RuO}_{2}$ pseudocapacitive ECs [16,17], respectively, those electrolytes are not applicable to $\mathrm{MnO}_{2} \cdot n \mathrm{H}_{2} \mathrm{O}$ ECs. $\mathrm{MnO}_{2} \cdot n \mathrm{H}_{2} \mathrm{O}$ readily dissolves either in strong acidic electrolytes or in strong alkaline electrolytes under high potentials.

In this paper, we have applied the gel electrolyte consisting of potassium poly(acrylate) (PAAK), $\mathrm{KCl}$ and water to $\mathrm{MnO}_{2} \cdot n \mathrm{H}_{2} \mathrm{O}$ ECs. With the selected compositions, the gel electrolyte possesses an ionic conductivity in the order of $10^{-1} \mathrm{~S} \mathrm{~cm}^{-1}$. The resulting gel electrolyte EC not only shows higher specific capacitance than the solution counterpart but also exhibit high-rate capability. PAAK-based gel electrolyte has previously been used only for $\mathrm{Ni} / \mathrm{MH}$ batteries and strong alkaline electric double-layer capacitors $[13,18]$. To our knowledge, this is the first success in applying gel electrolyte to $\mathrm{MnO}_{2} \cdot n \mathrm{H}_{2} \mathrm{O}$ ECs.

\section{Experimental}

$\mathrm{MnO}_{2} \cdot n \mathrm{H}_{2} \mathrm{O}$ particles were synthesized by mixing aqueous solutions of $\mathrm{KMnO}_{4}($ Nacalai, $99.3 \%)$ and $\mathrm{MnSO}_{4}$ (J.T. Baker, 
$99.3 \%$ with a $\mathrm{Mn}(\mathrm{VII}) / \mathrm{Mn}(\mathrm{II})$ molar ratio of $2: 3$ at room temperature. After being thoroughly washed with de-ionized water, the particles were finally heated at $200{ }^{\circ} \mathrm{C}$ in air for $1 \mathrm{~h}$. As determined by nitrogen adsorption, the resulting powder contains primarily meso-pores with pore volume of $\sim 0.25 \mathrm{cc} \mathrm{g}^{-1}$ and a BET surface area of $\sim 191 \mathrm{~m}^{2} \mathrm{~g}^{-1}$.

To prepare the electrode, slurry containing the oxide powder, acetylene black (AB; VULCAN XC72), and polyvinylidene difluoride (PVdF, Aldrich) was cast into film on Ti foils, and finally dried at $120^{\circ} \mathrm{C}$ for $6 \mathrm{~h}$ in vacuum. On the dry basis, the oxide to $\mathrm{AB}$ ratio was fixed at 7:3, while the binder, which used $\mathrm{N}$-methyl pyrrolidone (NMP, Mitsubishi Chemical) as the dispersing solvent, had a weight composition of $15 \%$ in the final electrode. Every electrode has a dimension of $1 \mathrm{~cm} \times 1 \mathrm{~cm}$ and contains approximately $1.7 \mathrm{mg}$ of dried overlay materials. The symmetric cell assembly consists of two electrodes with the overlays face-to-face separated by a silicone rubber spacer which is $3 \mathrm{~mm}$ thick.

The polymer component, PAAK, for forming the gel is used as purchased (CAS \#25608-12-2. Aldrich), and its chemical formula can be expressed as $-\left(\mathrm{CH}_{2}-\mathrm{CHCOOR}\right)_{n}-$. Dissolution of $1 \mathrm{~g}$ of the polymer in the presently used deionized water $(10 \mathrm{cc})$ changes the solution $\mathrm{pH}$ from 7.1 to 6.2. Estimation based on the dissociation equilibrium constant of either acetic acid $\left(\mathrm{p} K_{\mathrm{a}}=4.76\right)$ or propanoic acid $\left(\mathrm{p} K_{\mathrm{a}}=4.89\right)$ suggests that $>95 \%$ of $\mathrm{H}^{+}$has been ion-exchanged by $\mathrm{K}^{+}$at the $\mathrm{R}$-site in the formula shown above. For electrochemical characterization, the symmetric $\mathrm{MnO}_{2}$-cell was first immersed in $10 \mathrm{cc}$ of $1 \mathrm{M} \mathrm{KCl}$ aqueous solution, and $1 \mathrm{~g}$ of PAAK was subsequently added into the solution with stirring at room temperature. The resulting polymer gel electrolyte consists of 9 wt. \% PAAK, 6.7 wt. $\% \mathrm{KCl}, 84.3$ wt.\% $\mathrm{H}_{2} \mathrm{O}$.

Cyclic voltammetry (CV) curves were recorded by an electrochemical analyzer (Eco Chemie PGSTAT30). The average specific capacitance of the electrodes was calculated from the $\mathrm{CV}$ curve as follows:

$C_{\text {avg }}=2 \times \Delta Q(w \times \Delta V)^{-1}=2\left(\int I \mathrm{~d} V(S \times w \times \Delta V)^{-1}\right)$

where $\Delta Q$ is the total amount of charge accumulated over a potential window $\Delta V$ of a symmetric cell; $w$, the mass of active material in one electrode; $I$, the current; and $S$, the potential scan-rate. A factor of 2 is introduced because the capacitance exhibited by a symmetric cell is one half of the capacitance of each electrode. An AUTOLAB frequency response analyzer (AUTOLAB, Eco Chemie PGSTAT30) was employed for obtaining the electrochemical impedance spectra with the frequency range from $5 \mathrm{mHz}$ to $60 \mathrm{kHz}$ and a voltage amplitude of $10 \mathrm{mV}$. Electrolyte conductivity was determined from the impedance spectrum. Chrono-potential test was performed between 0 and $0.8 \mathrm{~V}$ at current density of $2 \mathrm{~mA} \mathrm{~cm}^{-2}$.

\section{Results and discussion}

Upon introducing the polymer into the $\mathrm{KCl}$ solution, the polymer swelled and the solution became increasingly viscous with time and eventually became rigid, showing no fluidity

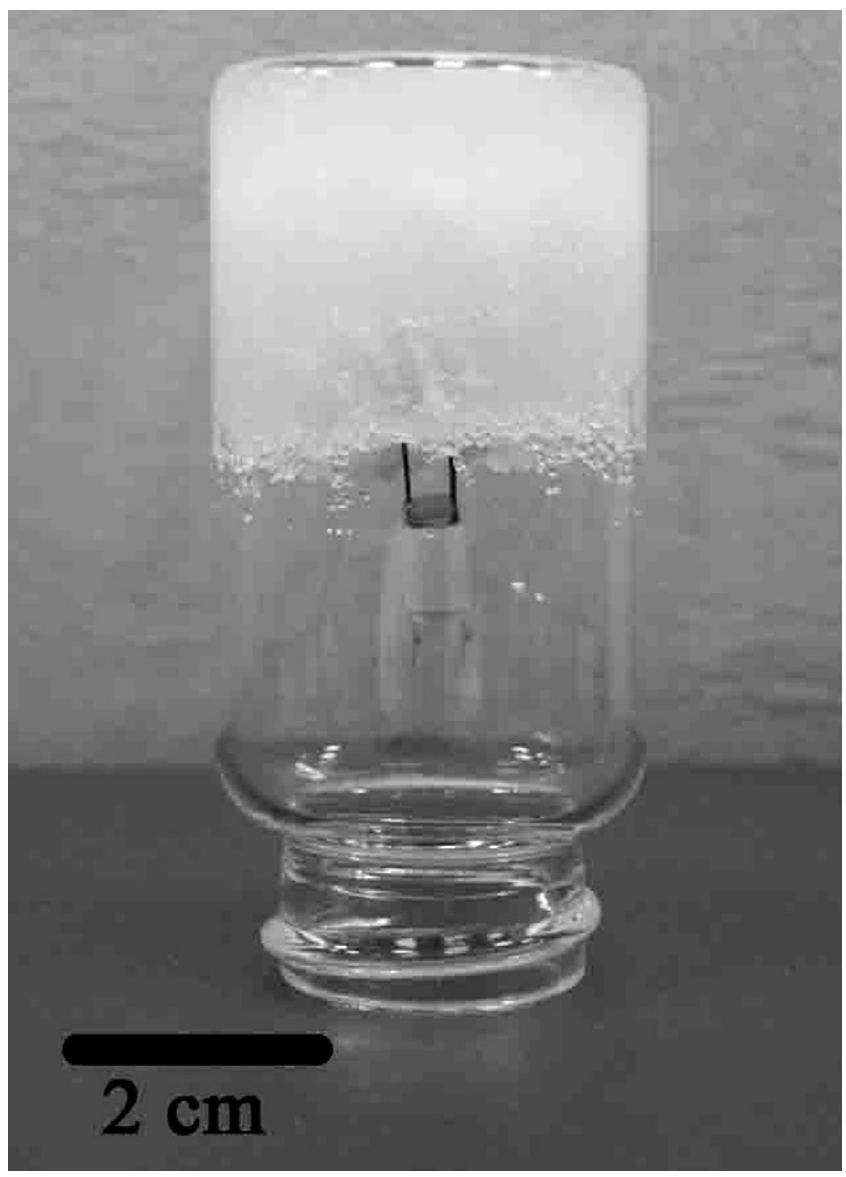

Fig. 1. The PAAK gel electrolyte along with a partially immersed electrochemical capacitor cell in a container in an upside-down position, showing no fluidity.

(Fig. 1). The voltammograms acquired with a liquid electrolyte $(1 \mathrm{M} \mathrm{KCl})$ and the gel electrolyte are shown in Fig. 2a and b, respectively. First, it can be seen that both electrolytes gave nearly rectangular current profiles, characteristic of a capacitor. Secondly, under the same scan rate, the gel electrolyte cell always exhibited higher capacitances than the solution one. For instance, by subtracting the contribution from the carbon component $\left(\sim 3.0 \mathrm{~F} \mathrm{~g} \mathrm{~g}^{-1}\right.$-composite), it can be shown that the oxide possesses a specific capacitance of $168 \mathrm{Fg}^{-1}$ in the gel electrolyte under the scan rate of $4 \mathrm{mV} \mathrm{s}^{-1}$ at room temperature $\left(\sim 27^{\circ} \mathrm{C}\right)$, and $116 \mathrm{Fg}^{-1}$ in the liquid electrolyte. The chronopotential curves acquired under constant current density in both electrolytes are shown in Fig. 3. Again, the linear line profile in both cases confirmed the nearly ideal capacitive behaviors.

Fig. 4 summarizes the effect of $\mathrm{CV}$ scan rate on the specific capacitance. Both electrolyte systems showed decreasing capacitance with increasing scan rate following a semi-logarithm correlation. However, the gel electrolyte system shows a slightly greater decreasing rate. Nevertheless, the specific capacitances of the gel electrolyte remain higher than those of the aqueous one throughout the range up to $200 \mathrm{mV} \mathrm{s}^{-1}$. In the gel electrolyte, the oxide electrode retains a specific capacitance of $101 \mathrm{Fg}^{-1}$ even at a scan rate of $200 \mathrm{mV} \mathrm{s}^{-1}$, which corresponds to a specific power of $\sim 16 \mathrm{~kW} \mathrm{~kg}^{-1}$ at $0.8 \mathrm{~V}$. 

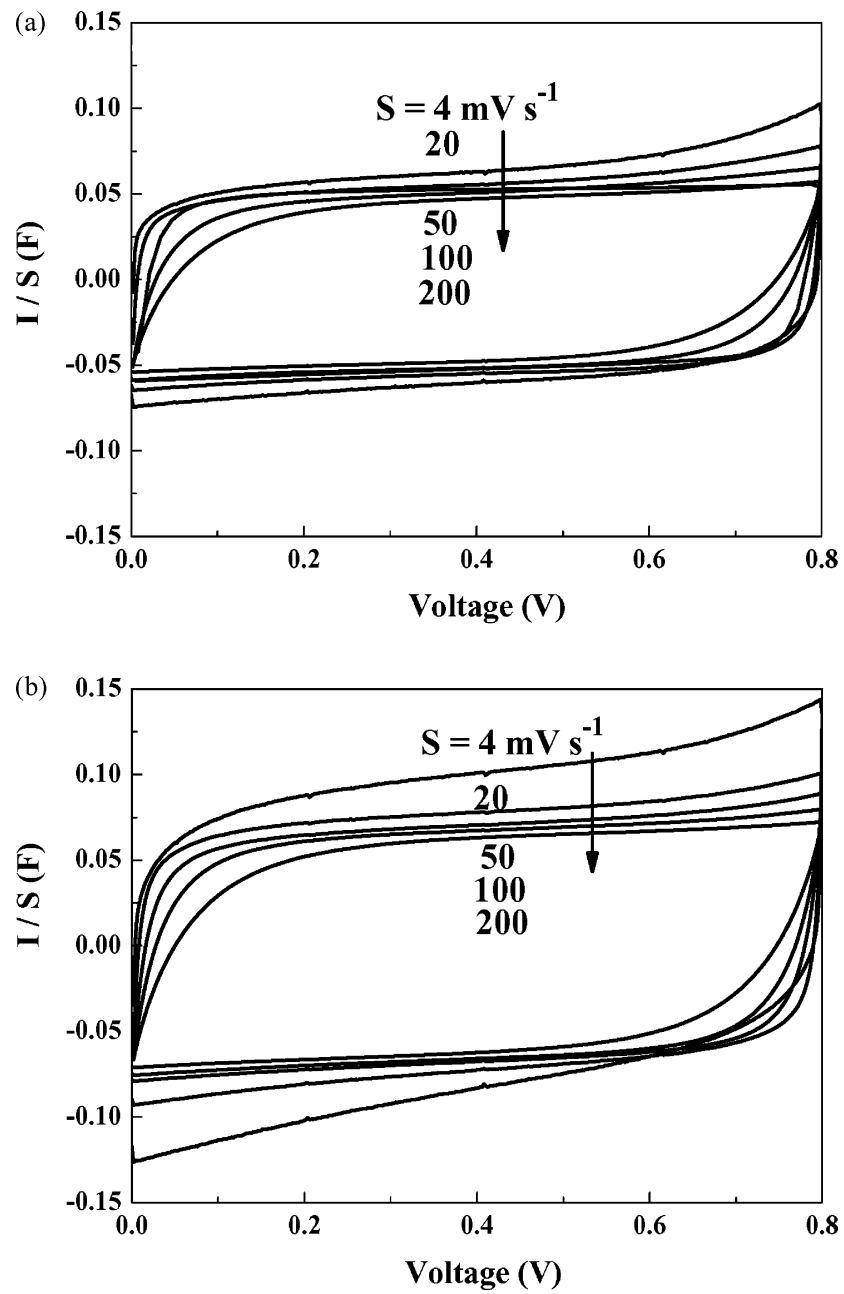

Fig. 2. Cyclic voltammograms for the cells with (a) the liquid solution and (b) the gel electrolyte.

The enhancement in specific capacitance by the gel electrolyte as described above is surprising but not unprecedented. In applying a PAAK-based gel electrolyte to carbon EDLCs, Nohara et al. [13] also observed slight increase in specific capac-

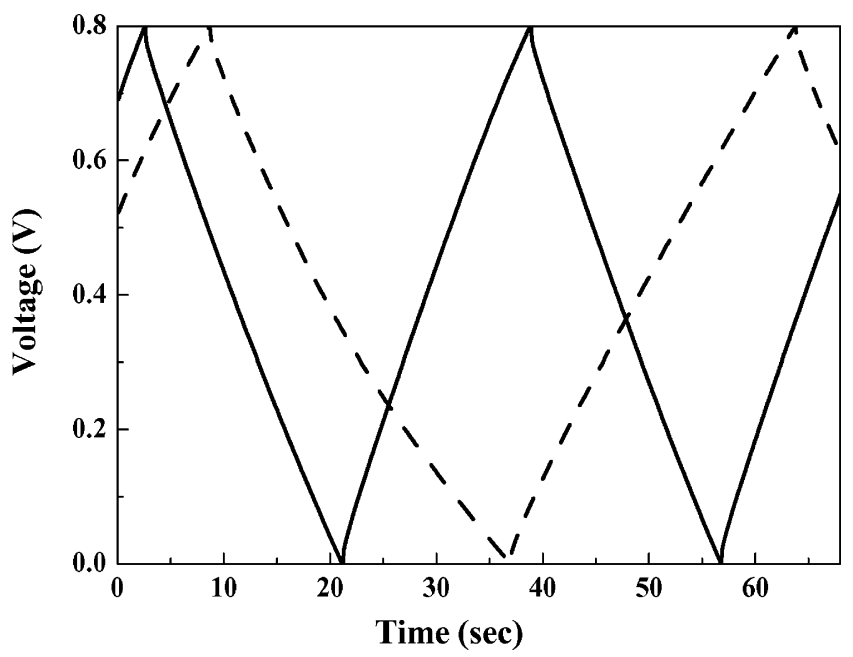

Fig. 3. The chrono-potential curves of the cells with (solid line) the liquid electrolyte and (dashed line) the gel electrolyte.

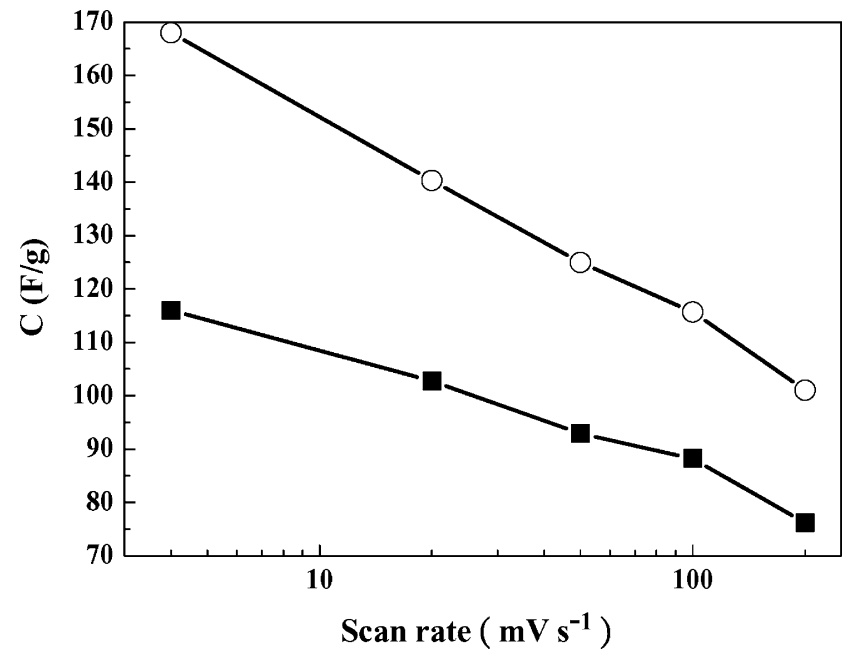

Fig. 4. Rate-dependent of capacitance. ( $\mathbf{\square}$ : the liquid electrolyte; $\bigcirc$ : the gel electrolyte).

itance when substituting an aqueous $\mathrm{KOH}$ electrolyte with the PAAK-based gel electrolyte containing the same alkaline salt. They attributed the enhancement to the occurrence of additional pseudocapacitance taking place only in the gel electrolyte, although the nature of the pseudocapacitance was not described.

As mentioned above, the polymer component contains $\mathrm{K}^{+}$ ions, and total $\mathrm{K}^{+}$content in the gel electrolyte is approximately 1.9 times that in the $1 \mathrm{M} \mathrm{KCl}$ solution. The effect of the excess $\mathrm{K}^{+}$ions on the capacitance of the $\mathrm{MnO}_{2}$ electrode was hence evaluated by using $\mathrm{KCl}$ liquid electrolytes of higher concentrations. As shown in Fig. 5, it was found that increasing $\mathrm{K}^{+}$ concentration actually reduces the specific capacitance at scan rates below $100 \mathrm{mV} \mathrm{s}^{-1}$. Therefore, the capacitance enhancement observed in the gel electrolyte is not due to the effect of excess $\mathrm{K}^{+}$. The cause to the capacitance reduction with increasing $\mathrm{K}^{+}$concentration is beyond the scope of this paper. However, it is worth mentioning that previous investigation [19] on the

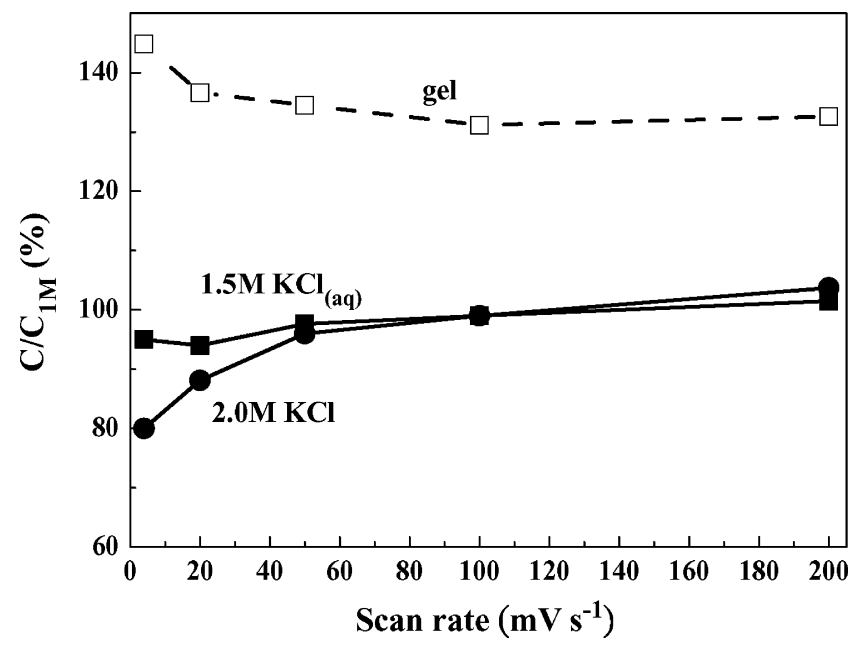

Fig. 5. Effect of $\mathrm{KCl}$ concentration on specific capacitance. The solid lines plot capacitance ratios $\left(C / C_{1 \mathrm{M}}\right)$ versus scan rates, where $C_{1 \mathrm{M}}$ represents the capacitance measured in $1 \mathrm{M} \mathrm{KCl}$ liquid electrolyte at the same scan rate. The dashed line plots the ratio for the gel electrolyte. 


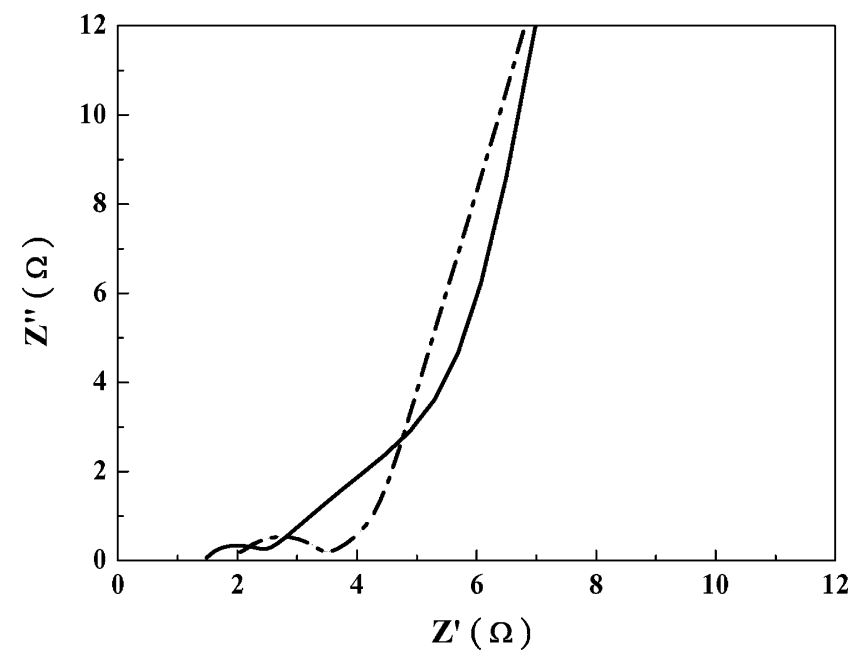

Fig. 6. Nyquist plots of the cells with (solid line) the liquid electrolyte and (dashed line) the gel electrolyte.

pseudocapacitance mechanism of $\mathrm{MnO}_{2} \cdot n \mathrm{H}_{2} \mathrm{O}$ EC has shown that the pseudocapacitance involves competitive intercalation of oxonium $\left(\mathrm{H}_{3} \mathrm{O}^{+}\right)$ions and the alkaline cations into the oxide matrix, and that the electrolyte containing the alkaline cation intercalating to a less extent generally gives a higher specific capacitance. Increasing $\mathrm{K}^{+}$concentration in the present study is expected to increase the extent of $\mathrm{K}^{+}$intercalation, and accordingly the specific capacitance falls. The slight enhancement in capacitance observed at $200 \mathrm{mV} \mathrm{s}^{-1}$ in Fig. 5 apparently results from improved solution conductivity, which becomes increasingly significant at high rates.

In order to understand the nature of the capacitance enhancement by the gel electrolyte, electrochemical impedance spectroscopic analysis was conducted. Fig. 6 shows the Nyquist plots for the liquid and gel electrolytes, respectively. The plots show similar fundamental components characteristic of a porous pseudocapacitor as depicted by Conway [20]. The semi-circle appearing within the high-frequency range in the plots can be accounted for by a parallel $R C$ equivalent-circuit unit of which $R$ corresponds to the charge-transfer resistance of the pseudocapacitance process and $C$, the double-layer capacitance at the electrode/electrolyte interface. The semi-circle is followed by a short segment that is inclined by nearly $\sim 45^{\circ}$. This segment is a signature of the porous nature of the electrode, and it can be accounted for by a transmission-line equivalent-circuit model that contains a $R C$ network to sum up the distributed pore resistances. Finally, the steep line toward the low frequency region arises from the pseudocapacitance.

The similarity in the charge transfer (semi-circle) resistance $(1.0-1.5 \Omega)$ may suggest that the electrochemical processes taking place at the oxide/electrolyte interface are essentially unchanged in these electrolytes. Major difference resides in the significant reduction in the distributed pore solution resistance (the $45^{\circ}$-inclined segment) for the gel electrolyte. The bulk electrolyte resistances, determined from the intersection of $Z^{\prime}$ and the front edge of the semi-circle, are 1.5 and $2.0 \Omega$, corresponding to conductivities of $2.0 \times 10^{-1}$ and $1.5 \times 10^{-1} \mathrm{~S} \mathrm{~cm}^{-1}$, for the liquid and gel electrolytes, respectively. That is, the presence of the polymer component only reduces the bulk conductivity, as expected. Therefore, the reduction in the pore resistance in the gel electrolyte is not related to the difference in solution conductivity. We conjecture two possible causes, which may relate the pore resistance reduction to the capacitance enhancement.

It is known that the use of hydrophobic binder, such as $\mathrm{PVdF}$ in the present study, reduces wetting compatibility between the aqueous electrolyte and the oxide electrode matrix, often resulting in pores within the electrode interior not fully wetted by the electrolyte solution. The hydrophobic nature of the polymeric component in the gel electrolyte may improve the compatibility between the electrode matrix and the electrolyte. As a result, in the gel electrolyte, the pores are better penetrated by the electrolyte, and the overall cell capacitance, hence increases due to reduced un-wetted areas. Alternatively, the swelling process of the polymer molecules within the electrode interior could open ajar closed pores that are originally not accessible to the electrolyte solution. This also results in increase in the overall cell capacitance. In both cases, because the pores are increasingly uniformly filled with the electrolyte, and the overall pore solution resistance is hence reduced. While these conjectures account for the impedance and capacitance data, more elaborated research is underway to further clarify these issues. Although the bulk conductivity, $1.5 \times 10^{-1} \mathrm{~S} \mathrm{~cm}^{-1}$, of the gel electrolyte is $25 \%$ lower than that of the liquid electrolyte, it is still much higher than those $\left(<10^{-2} \mathrm{~S} \mathrm{~cm}^{-1}\right)$ typically associated with polymeric solid electrolytes.

Finally, it should be pointed out that the presence of the polymer component does not impose negative effect on leakage current. For example, Fig. 7 shows the change in current necessary to maintain the cell at $0.8 \mathrm{~V}$. The leakage current in the gel electrolyte is in fact lower than that in $1 \mathrm{M} \mathrm{KCl}$ liquid electrolyte. Significant reduction in leakage current when liquid electrolyte is replaced with a gel one has also been noted in the $\mathrm{RuO}_{2}$ based ECs by Wada et al. [21] and Ni-metal hydride batteries by Iwakura et al. [22]. The mechanisms of self-discharge for ECs reported in the literature mainly include the shuttle reaction of impurity metal ions in electrolytes, short-circuit of electrode materials (e.g. carbon) penetrating the separator, and so on. In

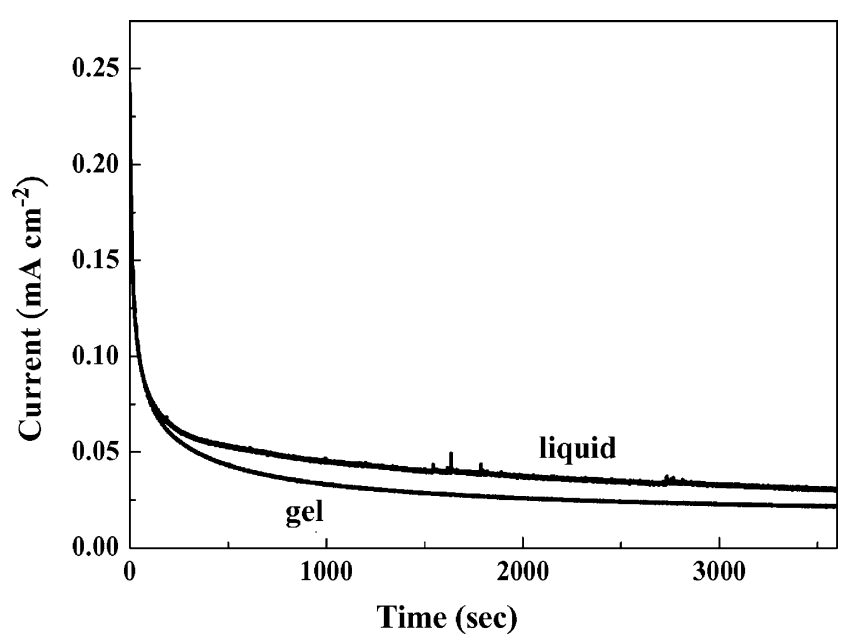

Fig. 7. Current versus time for cells maintained at $0.8 \mathrm{~V}$. 
the study by Wada et al. [21], the leakage current was attributed to the shuttle reaction of impurity $\mathrm{Fe}$ ions, and the use of the gel electrolyte, in replacing the liquid electrolyte counterpart, was suggested to restrain diffusion of the impurity ions and hence suppress the leakage current. In the present $\mathrm{MnO}_{2}$-based ECs, $\mathrm{Mn}$ ions in the range of $0.1-0.5 \mathrm{ppm}$ were detected in the liquid electrolytes, presumably dissolved by dispropornation reaction $[6,8]$. The leakage current might thus be related to the shuttle reaction of the impurity of $\mathrm{Mn}$ ions, and the similar restraineddiffusion model as suggested by Wada et al. [21] might also be operative in the present case to cause reduction in leakage current.

In summary, a PAAK-based aqueous gel electrolyte containing $\mathrm{KCl}$ has been demonstrated to be compatible to $\mathrm{MnO}_{2} \cdot n \mathrm{H}_{2} \mathrm{O}$ ECs. With the selected composition, PAAK: $\mathrm{KCl}: \mathrm{H}_{2} \mathrm{O}=9.0: 6.7: 84.3$ by weight, the gel electrolyte shows high rigidity and possesses an ionic conductivity in the order of $10^{-1} \mathrm{~S} \mathrm{~cm}^{-1}$. Compared with the aqueous solution electrolyte having the same salt $(\mathrm{KCl})$ composition, the gel electrolyte gives substantially higher capacitance and comparable rate capability. Although the study has used $\mathrm{KCl}$ as an example, it is believed that the PAAK-based gel electrolyte will be suitable for other salts, such as other alkali chlorides and sulfates, which have typically been used for $\mathrm{MnO}_{2} \cdot n \mathrm{H}_{2} \mathrm{O}$ ECs.

\section{Acknowledgments}

This work is supported by the National Science Council of Taiwan, R.O.C. (NSC 95-2221-E-002-350-MY3) and by National Taiwan University (95R0066-BE04-01).

\section{References}

[1] B.E. Conway, J. Electrochem. Soc. 138 (1991) 1539.

[2] B.E. Conway, V. Briss, J. Wojtowicz, J. Power Sources 66 (1997) 1.

[3] R. Kötz, M. Carlen, Electrochim. Acta 45 (2000) 2483.

[4] H.Y. Lee, J.B. Goodenough, J. Solid State Chem. 144 (1999) 220.

[5] H.Y. Lee, V. Manivannan, J.B. Goodenough, C. R. Acad. Sci. Paris t. 2, Série II c (1999) 565.

[6] R.N. Reddy, R.G. Reddy, J. Power Sources 124 (2003) 330.

[7] C.C. Hu, T.W. Tsou, Electrochem. Commun. 4 (2002) 105.

[8] S.C. Pan, M. Anderson, J. Mater. Res. 15 (2000) 2096.

[9] J.N. Broughton, M.J. Brett, Electrochim. Acta 49 (2004) 4439.

[10] J.P. Zhang, P.J. Cygan, T.R. Jow, J. Electrochem. Soc. 142 (1995) 2699.

[11] J.P. Zheng, T.R. Jow, J. Power Sources 62 (1996) 155.

[12] D. Kalpana, N.G. Renganathan, S. Pitchumani, J. Power Sources 157 (2006) 621.

[13] S. Nohara, H. Wada, N. Furukawa, H. Inoue, M. Morita, C. Iwakura, Electrochim. Acta 48 (2003) 749.

[14] A. Lewandowski, M. Zajder, E. Frackowiak, F. Bequin, Electrochim. Acta 46 (2001) 2777.

[15] M. Ishikawa, M. Ihara, M. Morita, Y. Matsuda, Electrochim. Acta 40 (1995) 2217.

[16] Y.-G. Wang, X.-G. Zhang, Electrochim. Acta 49 (2004) 1957.

[17] N.A. Choudhury, A.K. Shukla, S. Sampath, S. Pitchumani, J. Electrochem. Soc. 153 (2006) A614.

[18] S. Nohara, T. Asahina, H. Wada, N. Furukawa, H. Inoue, N. Sugoh, H. Iwasaki, C. Iwakura, J. Power Sources 157 (2006) 605.

[19] S.L. Kuo, N.L. Wu, J. Electrochem. Soc. 153 (2006) A1317.

[20] B.E. Conway, Electrochemical Supercapacitors: Scientific Fundamentals and Technological Applications, Plenum, New York, 1999, p. 384, 544.

[21] H. Wada, K. Yoshikawa, S. Nohara, N. Furukawa, H. Inoue, N. Sugoh, H. Iwasaki, C. Iwakura, J. Power Sources 159 (2006) 1464.

[22] C. Iwakura, N. Furukawa, T. Ohnishi, K. Sakamoto, S. Nohara, H. Inoue, Electrochemistry 69 (2001) 659. 